\title{
A new genus of Macrotomini (Coleoptera, Cerambycidae, Prioninae)
}

\author{
Antonio Santos-Silva ${ }^{1, \dagger}$, Maria Helena M. Galileo ${ }^{2, \ddagger}$ \\ I Museu de Zoologia, Universidade de São Paulo, São Paulo, 42494, 04218-970, São Paulo, São Paulo, Brazil \\ 2 Museu de Ciências Naturais, Fundação Zoobotânica do Rio Grande do Sul. CP 1188, 90001-970, Porto \\ Alegre, RS, Brazil \\ † urn:lsid:zoobank.org:author:E71CB0BE-4876-4BOB-ACAF-5AE13BA81E7E \\ ¥ urn:lsid:zoobank.org:author:FDEC7E34-A125-4765-A3EB-CF707CF104DC \\ Corresponding authors: Antonio Santos-Silva (toncriss@uol.com.br), Maria Helena M. Galileo (galileo@ \\ fzb.rs.gov.br) \\ Academic editor: A. Konstantinov | Received 3 November 2009 | Accepted 8 January 2009 | Published 2 February 2010 \\ urn:lsid:zoobank.org:pub:81E03083-8D2C-4000-838B-CA6C06187DD8 \\ Citation: Santos-Silva A, Galileo MHM (2010) A new genus of Macrotomini (Coleoptera, Cerambycidae, Prioninae). \\ ZooKeys 35: 65-75. doi: 10.3897/zookeys.35.312
}

\begin{abstract}
A new genus of Macrotomini (Coleoptera, Cerambycidae, Prioninae). Allomallodon gen. $\mathbf{n}$. is erected to accommodate Mallodon hermaphroditum Thomson, 1867, and M. popelairei Lameere, 1902. The assignment of this new genus to Macrotomini, and the validity of Mallodontini are discussed. As result, Mallodontini is considered a synonym of Macrotomini. A key to species of the new genus is included as well.
\end{abstract}

\section{Keywords}

Key, Mallodon, Mallodontini, new genus, taxonomy

\section{Introduction}

Thomson (1867) described Mallodon hermaphroditum, noting that it was the only species known in the genus whose male lacks impunctate and shining facets on the pronotum, in contrast with the remainder of the surface. Thus, the pronotum is simi- 
lar to that of the female. Later, Lameere (1902) transferred M. hermaphroditum to Stenodontes (Mallodon), described Stenodontes (Mallodon) popelairei, and noted that this species shows different characters, than Thomson's species. Some characters as, for example, body slender, labrum tumid, and prothorax in male without evident sexual dimorphism, allow to allocate these species in a new genus.

Since Lameere (op.cit.), both species were simply included in catalogues, and were not figured until Fragoso and Monné (1995) studied the lectotype male of $M$. hermaphroditum, and Santos-Silva (2005) examined the lectotype male and the paralectotypes (two males and one female) of $M$. popelairei. Neither of the latter two authors questioned the generic assignment of these species.

During the study of another genus (Nothopleurus Lacordaire, 1869), which included a cursory analysis of several species of Mallodon, it became evident that both $M$. hermaphroditum and $M$. popelairei exhibited an exclusive set of characters that would permit them to be assigned to a new genus. Further evidence is presented to support the inclusion of this new genus in Macrotomini, which includes Mallodontini, sensu Monné and Hovore (2006) and Monné (2006).

\section{Materials and methods}

Specimens examined for this study are from the following institutions / private collections:

ACMT American Coleoptera Museum (James Wappes), San Antonio, U.S.A.;

DHCO Daniel Heffern Collection, Houston, U.S.A.;

IRSN Institute Royal des Sciences Naturelles de Belgique, Brussels, Belgium;

MNHN Muséum National d'Histoire Naturelle, Paris, France;

MZSP Museu de Zoologia, Universidade de São Paulo, São Paulo, Brazil;

ZKCO Ziro Komiya Collection, Tokyo, Japan.

\section{Allomallodon gen. $\mathbf{n}$.}

urn:Isid:zoobank.org:act:82000311-6289-45AC-AE36-B50E563117B8

Etymology. Allo- $($ Greek$)=$ different, (i.e.) different from Mallodon. Gender masculine.

Type species. Mallodon hermaphroditum Thomson, 1867.

Size from small to large (up to $2 \mathrm{~cm}$ ). Integument brown to dark-brown.

Male (Figs 1, 3). Body not notably depressed; ratio of head (without mandibles) + prothorax and elytra equals to approximately 1:2.5. Head (Figs 1,3) proportionally large and wide; punctation of dorsal surface (Fig. 29) coarse, deep and confluent. Eyes large; upper ocular lobe just narrower than lower ocular lobe; distance between upper ocular lobes (Fig. 29) more than 1.2 times the length of scape; distance between lower ocular lobes approximately 1.4 times the length of scape. Ocular carina (Fig. 29) low, narrow and short, distinct only at vertical area of upper ocular lobe. Clypeus wide. La- 
brum vertical, but with the basal portion (Figs 6,10) wide, coplanar or almost coplanar with clypeus, tumid and distinctly visible in dorsal view. Hypostomal area coarsely and anastomosedly punctate. Galea surpassing base of second palpomere of maxillary

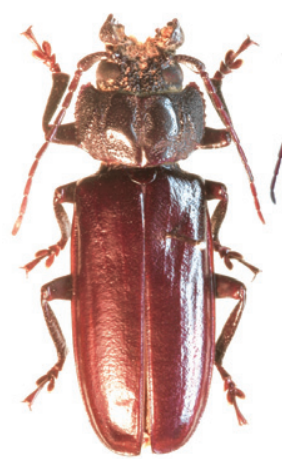

I

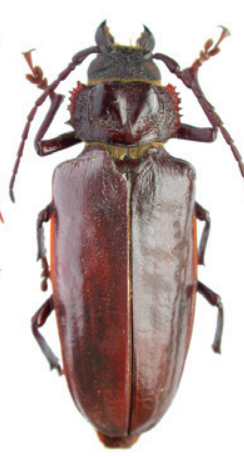

2

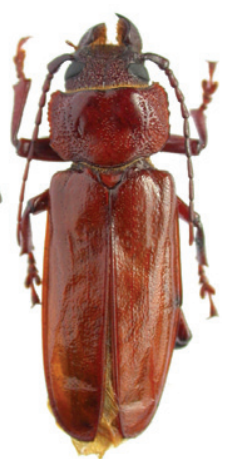

3
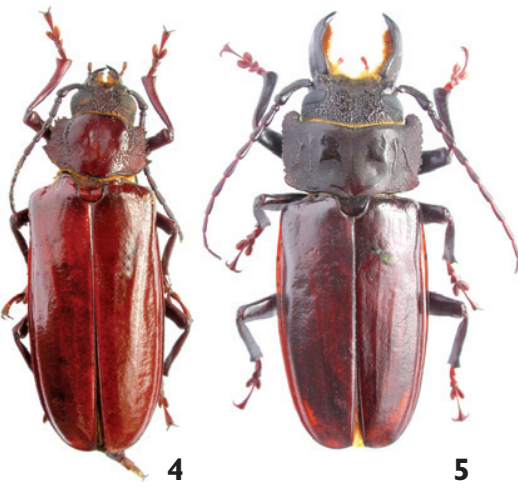

5

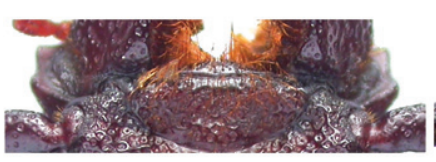

6

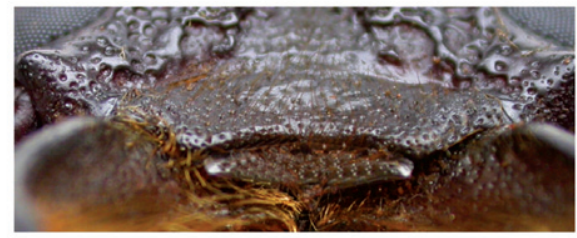

9

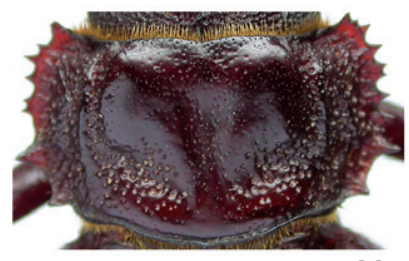

I I

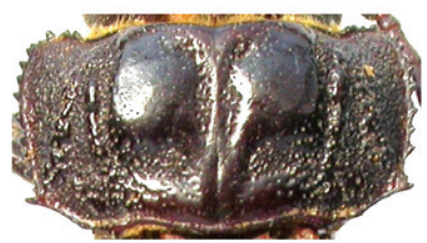

12

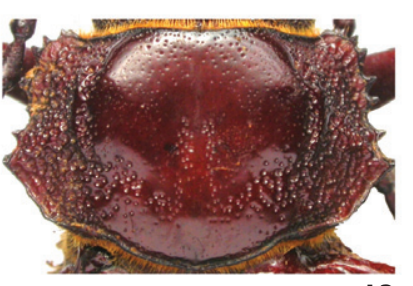

13

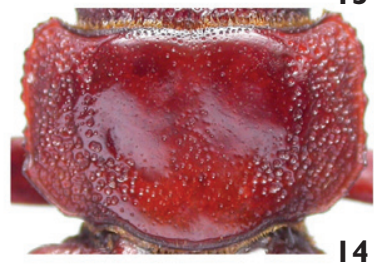

7

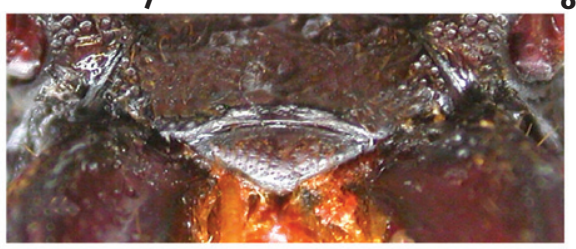

10

8
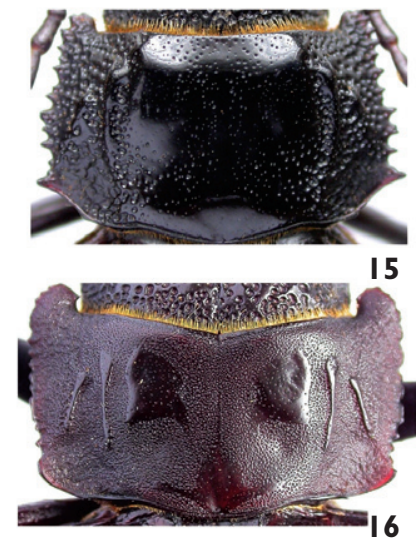

Figures I-I6. I-5 Habitus: I Allomallodon popelairei, male (photo by Ziro Komiya) $\mathbf{2}$ idem, female 3 A. hermaphroditum, male 4 idem, female 5 Mallodon spinibarbis, male 6-10 labro: 6 Allomallodon hermaphroditum, male, dorsal view 7 Mallodon spinibarbis, male, dorsal view 8 M. downesii Hope, 1843, male, dorsal view 9 M. spinibarbis, male, frontal view 10 Allomallodon popelairei, fêmea, frontal view I I-I6 Pronotum: I I Allomallodon popelairei, female $\mathbf{2}$ idem, male (photo by Ziro Komiya) I3 A. hermaphroditum, female $\mathbf{I} \mathbf{4}$ idem, male $\mathbf{I} \mathbf{5}$ Mallodon spinibarbis, female $\mathbf{I} \mathbf{6}$ idem, male. 
palps. Labial palps reaching approximately middle of palpomere III of maxillary palps. Mandibles (Figs 1, 3, 29), at most, as long as the head; dorsal carina (Fig. 29) elevated on basal two-thirds; inner face densely pilose; lower, inner margin projected in plate
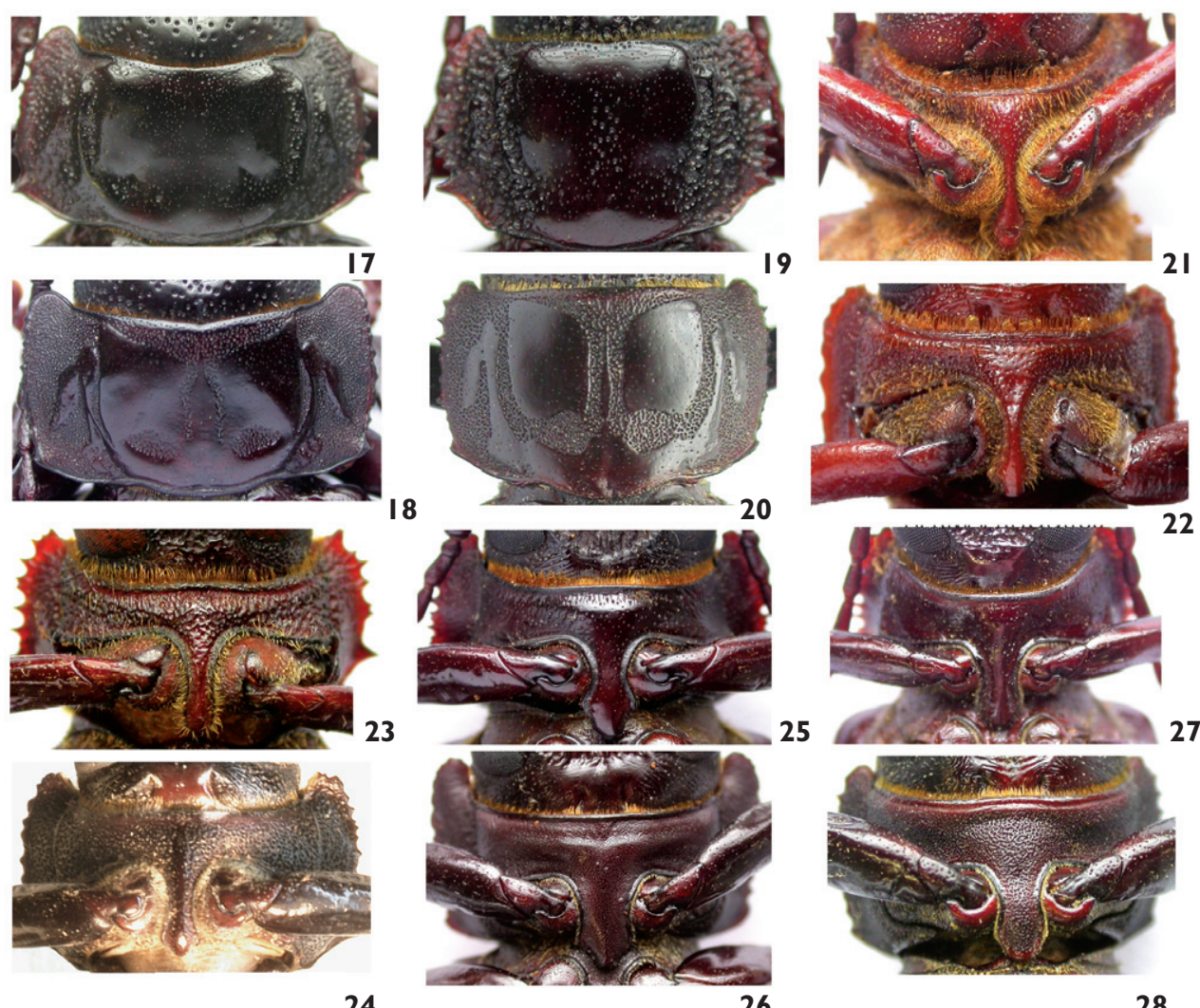

24

26

28

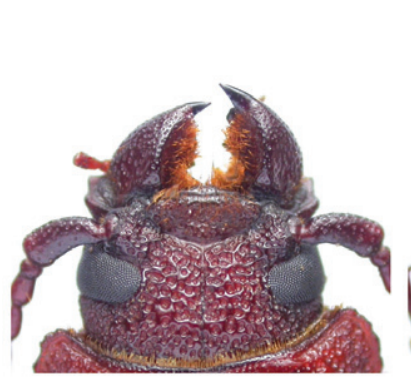

29

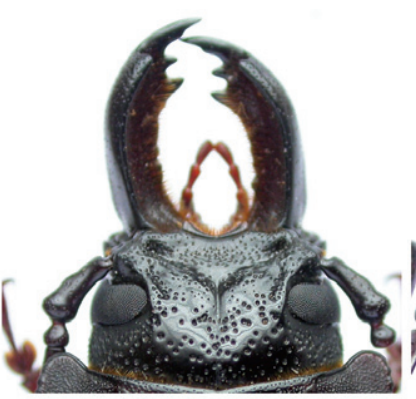

30

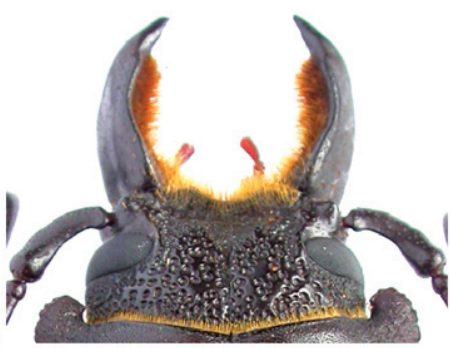

3 I

Figures 17-31. 17-20 Pronotum: 17 Mallodon downesii, female 18 idem, male 19 M. dasystomus dasystomus (Say, 1824). $\mathbf{2} \mathbf{I} \mathbf{- 2 8}$ prosternal process: $\mathbf{2} \mathbf{I}$ Allomallodon hermaphroditum, fêmea $\mathbf{2 2}$ idem, male 23 A. popelairei, female $\mathbf{2 4}$ idem, male (photo by Ziro Komiya) $\mathbf{2 5}$ Mallodon spinibarbis, female $\mathbf{2 6}$ idem, male $\mathbf{2 7}$ M. dasystomus dasystomus, female 28 idem, male. 29-3I head and mandibles, dorsal view: 29 Allomallodon hermaphroditum, male $\mathbf{3 0}$ Mallodon downesii $\mathbf{3}$ I M. spinibarbis. 
at apical two-thirds, where teeth are moderately large. Antennae (Figs 1, 3) attaining basal third of elytra or just surpassing; scape not surpassing the posterior edge of eye.

Prothorax transverse; anterior angles (Figs 12,14) projected forward, not notably wide, moderately acute at apex; lateral angles (Figs 12, 14) well marked, distinctly more elevated than the posterior angles in dorsal view; posterior angles well marked, obtuse. Pronotal disc (Figs 12, 14) without sexual dimorphism (sexual punctation), without impunctate and shining facets in contrast with the remainder of the central surface; lateral rugose-punctate; lateral margins crenulated between the anterior lateral angles. Proepimera, proepisterna, and lateral of prosternum (Figs 22, 24) moderately, coarsely and confluently punctate, finer than that of lateral areas of pronotum; central area of prosternum finer and more sparsely punctate than laterally. Prosternal process (Figs 22, 24) distinctly narrowed medially. Metepisterna and lateral areas of metasternum moderately, densely, pilose with long hairs. Metepisterna wide (width at central region equal to approximately 0.3 times the length); inner margin subvertical. Femora and tibiae unarmed.

Female (Figs 2, 4). Eyes proportionally larger than in male. Distance between upper ocular lobes equal to length of scape; distance between lower ocular lobes just greater than the length of scape or subequal. Antennae (Figs 2, 4) slightly shorter than in male. Lateral margins of pronotum crenulate (Figs 11, 13), more acute and projected than in male. Proepisterna and proepimera (Figs 21, 23) rugose or slightly rugose, not punctate or with coarse punctures near the prosternum. Punctation of prosternum similar to that of male. Prosternal process, metasternum and metepisterna (Figs 21, 23) as in male.

Included species: Allomallodon hermaphroditum (Thomson, 1867); A. popelairei (Lameere, 1902).

\section{Material examined:}

Allomallodon hermaphroditum. ECUADOR, Pichincha: Santo Domingo de los Colorados, 3 \%, III.1982, [no collector indicated] (MZSP). COLOMBIA, ${ }^{\circ}$, [no date and collector indicated] (MZSP). Santander: Bucaramanga (958 m; 707'17"N, 7307'33"W), q, VII.29.1973, H. Arévalo col. (MZSP). Valle del Cauca: CalimaDarién (Cristalina Alta), đ̃, o, VII.21-28.1992, several collectors (MZSP). Additionally we examined photographs of the lectotype male currently deposited at MNHN.

Allomallodon popelairei. PERU, Cusco: Limatambo, o, III.01.1965, [no collector indicated] (MZSP); Huanaco (probably in Cusco), lectotype $\widehat{\jmath}, 3$ paralectotypes $(2 \hat{O}, 1$ ) ) [no date and collector indicated] (IRSN). Additionally we examined photographs of two males sent by Ziro Komyia (Japan), from his private collection.

Geographical distribution: Peru, Colombia, and Ecuador.

Diagnosis and Discussion. Allomallodon gen. n. differs from Mallodon Lacordaire, 1830 by the following characters: body (Figs 1-4) slender; mandibles of male (Fig. 29), at most, as long as the head; base of labrum (Figs 6, 10, 29) distinctly visible in dorsal view, coplanar or nearly so with the clypeus; labrum (Fig. 10) tumid; lateral angles of prothorax of male (Figs 12,14) distinctly more elevated than posterior angles in line; pronotum (Figs 12, 14), proepimera and prosternum (Figs 22, 24) of male without 
evident sexual dimorphism; prosternal process (Figs 21-24) distinctly narrowed medially. In Mallodon body, in general, more robust (Fig. 5); mandibles of major male (Figs 30, 31) longer than the head; base of labrum (Fig. 7) not visible in dorsal view or when visible (Fig. 8), more distinct laterally, with its basal margin placed, in general, distinctly lower than the edge of clypeus (Fig. 9), and always strongly concave at middle region; lateral angles of prothorax of male (Figs 16, 18) placed in the same line or almost in the same line of posterior ones (sometimes, similar to the species of Allomallodon (Fig. 20)); pronotum, proepimera and prosternum of male (Figs 26, 27) with sexual dimorphism very distinct; prosternal process (Figs 25-28) wide and not or, slightly narrowed medially (in female of some species, narrowed medially, but always moderately wide).

Allomallodon differs from the species of Nothopleurus Lacordaire, 1869 [Group of Maxillosus: N. maxillosus (Drury, 1773); N. bituberculatus (Palissot de Beauvois, 1805); N. subcancellatus (Thomson, 1867); N. santacruzensis Hovore \& Santos-Silva, 2004], by the absence of sexual punctation in prothorax of males, and by the metepisterna of male wider (width at central region equal to approximately 0.3 times the length). In males of Nothopleurus (Group of Maxillosus) the prothorax has sexual punctation, and the metepisterna is narrower (width at central region equal to approximately 0.25 times the length).

From the species of Physopleurus Lacordaire, 1869 with unarmed tibiae, Allomallodon differs, mainly, by the prosternal suture straight or substraight, and by the prosternum not tumid. In all species of Physopleurus the prosternal suture is distinctly curved, and the prosternum is tumid or strongly tumid.

Allomallodon differs from Mallodonhoplus Thomson, 1861 by the unarmed tibiae (distinctly spinose, mainly the protibiae, in Mallodonhoplus). It can be separated from the species of Stenodontes Audinet-Serville, 1832 by the shorter antennae that do not reach the middle of elytra. In males of Stenodontes the antennae surpass the middle of the elytra, and in females they reach the middle. It differs from Neomallodon Linsley, 1957 by the pronotum of male being distinctly and abundantly punctate laterally (slightly rugose in Neomallodon). From the species of Olethrius Thomson, 1861 it differs, mainly, by the scape not surpassing the posterior edge of eye (distinctly surpassing in Olethrius).

Fragoso and Monné (1995) noted the following on the pronotum of A. hermaphroditum: "Besides the inappropriate epithet, the male pronotal disc shows a large, subcircular "tache luisante", with a cluster of points in the middle, as well as a few other points scattered at the periphery of the disc (latero-posteriorly more numerous); the sex-points are limited to lateral areas, close to pronotal bordes (including the "oreilletes")". These statements, however, are not consistent with the lectotype and specimens examined by us. In fact, the epithet chosen by Thomson is quite appropriate, as the sexual dimorphism in the pronotum is minimal and, above all, there is no the sexual punctation as noted by Fragoso and Monné (op.cit.). The entire sculpture of pronotal disc is quite similar in both sexes of $A$. hermaphroditum (Figs 13, 14), as well as in $A$. popelairei (Figs 11,12), and very different from what occurs in other species of Mallodon (Figs 15-20), in which the sexual dimorphism is strongly evident. 


\section{On the placement of Allomallodon gen. $n$.}

Allomallodon belongs to the group that some authors (primarily European) exclude from Macrotomini, and include in Mallodontini. Although it may seem obvious that a genus carved out of Mallodon belongs to that group, such an assertions, in some cases, can be misleading. Prioninae is a small subfamily in comparison with other cerambycid subfamilies, but the relationship and placement of the genera and species, frequently, are complex. That, in our opinion, is the reason by which Mallodontini is not a well defined group, as suggested by some authors, for example Vitali (2008): "The systematics of the Macrotomini, already partially cleared by European authors (Thomson, Lameere, Quintin [sic], Villiers), still shows uncertainties due to the fact that the American authors (Monné and Hovore 2005; Silva-Santos [sic] and Martins 2005) still consider Macrotomini, Mallodontini and others only one tribe".

Thomson (1861) erected the group "Mallodonitae" (currently considered Mallodontini) and defining it by the following: head wide, not elongated behind eyes; antennae short, filiform or submoniliform, with the antennomere III short, and barely longer or equal to IV; mandible subvertical or horizontal, robust, frequently elongated; lateral margins of prothorax crenulated or multi-spinose; elytron elongated, subdepressed; prosternum distinct; mesosternum flat; legs cylindrical; protibiae unarmed (except in Mallodonhoplus); tarsi mediocre, with the tarsomere V usually not longer than I-IV together. Thomson (op.cit.) included in this group Chiasmus Thomson, 1861 (currently Chiasmetes Pascoe, 1867); Basitoxus Audinet-Serville, 1832; Colpoderus Audinet-Serville, 1832 (= Notophysis Audinet-Serville, 1832); Archetypus Thomson, 1861; Mallodon Lacordaire, 1830; Mallodonhoplus Thomson, 1861; Aplagiognathus Thomson, 1861; Platygnathus Audinet-Serville, 1832; and Hystatus Thomson, 1861.

According to Thomson (op.cit.), the characters of "Macrotomitis" that allow separation from "Mallodonitae" are: antennae longer, with antennomere III distinctly longer than IV; upper ocular lobes closer; mandibles not transversal; protibia often with spines and different. The genera that were included in "Mallodonitae" make the group an amalgam of tribes, as currently accepted, be they by European or American authors: Macrotomini, Macrotomini/Mallodontini, Notophysini, Eurypodini, Platygnathini. Thus, the only merit of Thomson's (op.cit.) regarding "Mallodonitae" was to attribute a name to the group, without contributing substantively to the classification of Prioninae, as noted by Vitali (2008).

Following his previous classification, Thomson (1864) redefined "Mallodonitae" with the following changes sensu Thomson (1861): body wide, mainly in males; antennae just surpassing the middle of elytron (sometimes, shorter); scape thick, longer or as long as the antennomere III; pronotum in male with smooth facets, and scabrous or punctate in female; prosternal process slightly projected; mesosternal process laminiform; legs never with spines [mainly modification]; tarsomere $\mathrm{V}$ as long as I-IV together; integument always brownish, shining. Thomson (1864) included in this group the genera recorded in Thomson (1861), except Mallodonhoplus (transferred to "Mac- 
rotomitae"), and added Opheltes Thomson, 1864. Again, this concept joins genera that currently are included in many tribes of Prioninae.

According to Thomson (1867) "les Mallodonites se distinguent des MacrotoMITEs, leurs plus proches voisins, par les pattes qui sont toujours inermes dans les deux sexes". As in his earlier works, Thomson maintained in "Mallodonites" the same genera (excluding Mallodonhoplus), and included Cronodagus Thomson, 1867 (= Cacodacnus Thomson, 1861).

This concept of Mallodontini, based mainly on the absence of spines on the legs, is very unsatisfactory, and usually does not allow to reliably separat included genera. For example, in Physopleurus there are species with spines on tibiae as well as species with the tibiae unarmed. Many other characters are shared by these two species groups of Physopleurus (apex of antennal tubercles sub-horizontal and backward; prosternal suture absent or present and distinctly curved in males, etc), which does not allow the division in two genera, much less the inclusion of these species in different tribes. It is important highlight that the species of Physopleurus show a general appearance similar to that of the species of Mallodon and often have facets on pronotum of males, mentioned by Thomson (1864), as well as all other characters pointed out by Thomson $(1861,1864)$. In the description of Mallodon hermaphroditum, a species that does not have facets on the pronotum of males, demonstrates that Thomson was deliberately modifying the description of Mallodontini in each of his works, including and excluding genera. This exposes the fragility of the classification of this group that, as previously seen by the concept of Thomson (1867), differs from Macrotomini only by the unarmed legs.

Lameere (1919) summarized his previous works ("Révision des prionides") and divided Macrotomini in several groups that currently are considered subtribes by some authors, and tribes by others: Archetypi; Basitoxi; Stenodontes; Cnemoplites; Macrotomae; Rhaphipodi; and Xixuthri. According to him, the subgroup "Stenodontes" is characterized: body, in general, large, more or less depressed; eyes not emarginated; antennal tubercle distinct and acute; scape elongated and longer than the antennomere III; mandibles with dorsal carina; ligulae small and weakly whole (almost undivided); prothorax wide, with the sides wide and a little bent down, lateral edge present and crenate, more parallel in male than in female; males with sexual punctation on prothorax; pronotum of males with callosities shining; legs robust, with or without spines; last urosternite of males more or less emarginated. As shown above, Lameere (op.cit.) modified the concept of Macrotomini and Mallodontini established in the works of Thomson considerably. In particular, the main character used by Thomson (1867) to separate these two groups, was not accepted by Lameere (op.cit.), because the subgroup "Stenodontes", that included Mallodon, has species with legs that are spinose or not.

As in the divisions established in Thomson's works, the division proposed by Lameere maintains separate genera that share many characters (e.g. Xixuthrus Thomson, 1864 and Mecosarthron Buquet, 1840), and combined other genera with notably different characters (e.g. some species of Nothopleurus, and Mallodon).

Despite showing inconsistencies in his descriptions of tribes, in which were included genera that contradict the characters that were noted (e.g. body more or less 
depressed in "Archetypi", in relation to Strongylaspis Thomson, 1861, whose species has body distinctly not depressed), the concept of "Stenodontes" proposed by Lameere is more consistent than that of Thomson, because it unites genera with generally similar shared characters (body form, length of scape in relation to the antennomere III, prothorax form, etc).

Quentin and Villiers (1975) considered Macrotomini and Mallodontini as distinct and, in their key to the tribes that occur in Madagascar, separated these groups in the following manner: pronotum flat, with sides explanate in Mallodontini, and convex and with the sides bent down in Macrotomini; presence of shining facets on pronotum of males, occupying almost the whole surface in Mallodontini, and without facets or with small facets in Macrotomini. That key, if applied to American genera, would separate into distinct tribes species in the same genus, including species that at that time were in Mallodon, as well as genera included in the subgroup "Stenodontes" by Lameere (1919). According to Quentin and Villiers (op.cit.), Mallodontini is characterized by: general form wide and depressed; eyes not or slightly emarginated, coarsely faceted, weakly protruding, not surpassing the antennal tubercles; antennae with eleven segments, filiform, rarely surpassing the middle of elytra; scape, at least, as long as antennomere III; prothorax transverse, explanate laterally; pronotal disc, mainly in males, with facets or callosities flat and shining; prothoracic episterna very wide; legs, in general, short and always unarmed. It is important to note that Quentin and Villiers (op.cit.) characterized the tribe not only for the single species present in Madagascar. This definition of Mallodontini distinctly modifies, again, the limits of the group, resulting in the mandatory exclusion of genera included by Lameere (1919): Nothopleurus (part); Physopleurus; Mallodonhoplus; Olethrius; and Allomallodon gen. n. (originally included in Mallodon). Moreover, it may include species in genera that, by the definition of European authorities, could not belong to Mallodontini, as for example, Physopleurus rugosus (Gahan, 1894) and P. longiscapus Lameere, 1912, in which the proepisterna is not notably reduced and has all the other characters listed by Quentin and Villiers (op. cit.). Seemingly contradictory, Villiers (1980) allocated Nothopleurus in Mallodontini, without realizing that the type species of this genus, Nothopleurus ebeninus Lacordaire, 1869, does not fit to his description of the tribe, primarily, by the pronotum of males is without impunctate and shining facets in contrast with the remainder of surface.

As shown above, the divisions proposed, in part by European authors, affirmed the opinion of Vitali (op.cit.) (Mallodontini different from Macrotomini), and did not "clear [up]" the classification of Macrotomini. In fact it has made it more chaotic, mainly by contradicting the vastly different concepts of Thomson $(1861,1864,1867)$, Lameere (1919) and Quentin and Villiers (1975).

It is probable that Macrotomini is not a monophyletic group, but the divisions proposed up to now are inconsistent. Thus, we believe that the prudent action is to maintain Macrotomini as a single tribe, including and disregarding the subdivisions presented in Lameere (1919). Monné and Hovore (2006) listed the American genera of Macrotomini, following the concept of American authors. 


\section{Key to the species of Allomallodon}

1. Mandibles tumid on outer face (Figs 1,2); shining callosity on pronotal disc divided at middle by distinct or moderately distinct furrow (Figs 11, 12). Peru A. popelairei (Lameere, 1902)

- $\quad$ Mandibles not tumid on outer face (Figs 3, 4); shining callosity on pronotal disc not or barely divided at middle by furrow (Figs 13, 14). Colombia, Ecuador A. hermaphroditum (Thomson, 1867)

\section{Acknowledgements}

To Ziro Komiya (ZKCO) for the photographs of the specimens of Allomallodon popelairei. To James Wappes (ACMT), Daniel Heffern (DHCO), and Alain Drumont (IRSN) for sending the material as loan. Special thanks to Ian Swift (Department of Watershed and Lands, Contra Costa Water District, Concord, California, USA) for the comments and English corrections in the manuscript.

\section{References}

Fragoso SA, Monné MA (1995) Notes on Macrotomini (Coleoptera, Cerambycidae, Prioninae). Revista Brasileira de Biologia 55: 215-225.

Lameere AAL (1902) Révision des Prionides. Quatrième Mémoire - Sténodontines. Mémoires de la Société Entomologique de Belgique 9: 63-110.

Lameere AAL (1919) Famille Cerambycidae: subfam. Prioninae. Coleoptera. In: Wytsman P (Ed) Genera insectorum. Belgique, (172): 1-189, pls. 1-8.

Monné MA (2006) Catalogue of the Cerambycidae (Coleoptera) of the Neotropical Region. Part III. Subfamilies Parandrinae, Prioninae, Anoplodermatinae, Aseminae, Spondylinae, Lepturinae, Oxypeltinae, and addenda to the Cerambycinae and Lamiinae. Zootaxa 1212: 1-244.

Monné MA, Hovore FT (2006) Checklist of the Cerambycidae, or longhorned wood-boring beetles, of the Western Hemisphere. Rancho Dominguez, Bio Quip Publications, 394 p.

Quentin RM, Villiers A (1975) Faune de Madagascar (Pars 40). Orstom, Paris, 251 p.

Santos-Silva A (2005) Redescrição de Mallodon popelairei (Lameere, 1902) (Coleoptera, Cerambycidae, Prioninae). Papéis Avulsos de Zoologia 45: 249-254.

Thomson J (1860-1861) Essai d'une classification de la famille des cérambycides et matériaux pour servir à une monographie de cette famille. Paris, 396 pp. +3 pls. [1860: pp. xvi + 128; 1861: pp. 129-396].

Thomson J (1864-65) Systema cerambycidarum ou exposé de tous les genres compris dans la famille des cérambycides et familles limitrophes. Mémoires de la Société Royale des Sciences de Liège 19: 1-578 [1864: pp. 1-352; 1865: pp. 353-578].

Thomson J (1867) IV. Révision du groupe des Mallodonites (Insectes Coléoptères, Prionites, Cérambycides). Physis Recueil d'Histoire Naturelle (2)1: 85-106. 
Villiers A (1980) Coléoptères Cerambycidae des Antilles Françaises I. Parandrinae, Prioninae, Lepturinae. Annales de la Société Entomologique de France (n.s.) 16: 133-157.

Vitali F (2008) Taxonomic and faunistic notes about the genus Olethrius Thomson, 1860 (Coleoptera, Cerambycidae). Entomapeiron (P.S.) 2: 1-32. 